\title{
The use of PEGylated liposomes in the development of drug delivery applications for the treatment of hemophilia
}

This article was published in the following Dove Press journal:

International Journal of Nanomedicine

5 August 2010

Number of times this article has been viewed

\author{
Rivka Yatuv \\ Micah Robinson \\ Inbal Dayan-Tarshish \\ Moshe Baru \\ Omri Laboratories Ltd., Nes Ziona, \\ Israel
}

Correspondence: Moshe Baru

Omri Laboratories Ltd, Bldg. 22, Weizmann

Science Park, PO Box 40I5, NesZiona

$74 \mid 40$, Israel

Tel +972 89302970

Fax +972 89302975

Email moshe@omrilabs.co.il

\begin{abstract}
Hemophilia A is a rare X-linked bleeding disorder caused by lack or dysfunction of coagulation factor VIII (FVIII). Hemophilia A is treated with replacement therapy, but frequent injections of the missing FVIII often lead to the formation of inhibitory antibodies. Patients who develop high levels of inhibitors must be treated with bypassing agents such as activated FVII (FVIIa). Both FVIII and FVIIa have short half-lives and require multiple injections. Long-acting forms of these proteins would therefore reduce the frequency of injections, improve patient compliance and reduce complications. In this article we present a new platform technology that produces long-acting forms of FVIII and FVIIa and improves the efficacy of hemophilia treatment. This technology is based on the binding of proteins/peptides to the outer surface of PEGylated liposomes (PEGLip). Binding is dependent on an amino acid consensus sequence within the proteins and is highly specific. At the same time, binding is non-covalent and does not require any modification of the therapeutic agent or its production process. Association of proteins with PEGLip results in substantial enhancements in their pharmacodynamic properties following administration. These improvements seem to arise from the association of formulated proteins with platelets prior to induction of coagulation.
\end{abstract}

Keywords: PEGylated liposomes, therapeutic proteins, pharmacodynamics, factor VIII, factor VIIa

\section{Introduction}

\section{Hemophilia}

Hemophilia is an inherited bleeding disorder caused by the lack or dysfunction of coagulation factors VIII (FVIII) or IX (FIX). The genes for FVIII and FIX are located on the $\mathrm{X}$ chromosome, and the vast majority of individuals with hemophilia are males. Hemophilia A accounts for approximately $75 \%-80 \%$ of all hemophilia cases with a prevalence of approximately $1 / 10,000$ in the male population, whereas the prevalence of hemophilia B is $1 / 30,000 .^{1,2}$ The severity of the bleeding tendency is determined by the residual clotting factor activity. Approximately $40 \%$ of hemophilia patients have a severe form of the disease, defined as having less than $1 \%(0.01 \mathrm{IU} / \mathrm{ml})$ of normal factor activity. ${ }^{3}$

Hemophilia patients experience spontaneous hemorrhages into the joints, particularly the weight bearing joints such as knees, ankles and hips. This bleeding is painful and leads to long term inflammation and deterioration of the joint, resulting in permanent deformities, misalignment and loss of mobility. This is the major complication of hemophilia..$^{4,5}$ Bleeding may also occur into the muscles, soft tissues and other organs. 


\section{Hemophilia therapy}

Hemophilia is treated by supplying patients with the missing coagulation factor (FVIII or FIX). Replacement therapy may be provided on-demand (to stop a bleed) or prophylactically (to prevent bleeds). When treatment is provided on-demand, injections must be initiated at the first onset of symptoms so as to limit both the amount of bleeding and the extent of the resulting tissue damage. ${ }^{6}$ Prophylactic treatment has been shown to provide hemophilia patients with better overall care than on-demand treatment as it reduces the frequency of hemorrhages and slows the development of long term arthropathy. ${ }^{7}$ However, prophylactic treatment is more expensive than on-demand treatment and is not accessible to many patients. ${ }^{6}$

In this review, we focus on the treatment of hemophilia A, the most common form of the disease. The FVIII used to treat hemophilia A may be produced in mammalian cell lines genetically engineered to synthesize human FVIII (recombinant FVIII, rFVIII) or may be purified from normal pooled plasma (plasma-derived FVIII, pdFVIII). ${ }^{8}$

FVIII is a large glycoprotein (2332 amino acids) that is synthesized as a $330 \mathrm{kDa}$ precursor and undergoes multiple processing steps to yield a heterodimer composed of a light chain $(80 \mathrm{kDa})$ and a heterogeneous heavy chain (90-210 kDa) $)^{9}$ FVIII circulates in the plasma as an inactive precursor, tightly complexed with von Willebrand factor (vWF). Upon initiation of coagulation, FVIII is activated by thrombin. It dissociates from vWF, interacts with negatively charged phospholipids on the surface of activated platelets, and acts as a cofactor for factor IXa in the activation of factor X. ${ }^{1}$ This in turn leads to the generation of substantial amounts of thrombin, the key enzyme in the coagulation cascade, and to the generation of a hemostatic plug.

The half-life of human FVIII is about 10-12 hours. ${ }^{10,11}$ Effective prophylactic therapy therefore requires three weekly infusions of 20-40 IU/kg to maintain FVIII above levels at which spontaneous bleeding occurs. ${ }^{7}$ The need for frequent infusions reduces quality of life and may lead to problems with compliance and injection complications. ${ }^{12}$ Central venous access devices are frequently required, especially in children, but these devices are plagued by recurrent infections and thrombosis. ${ }^{13}$

\section{Development of inhibitors and acquired hemophilia}

Replacement treatment is complicated by the emergence of antibodies that inhibit the activity of the injected protein. ${ }^{14}$ Approximately $20 \%-40 \%$ of hemophilia A patients and
$2 \%-3 \%$ of hemophilia B patients develop inhibitors. ${ }^{15,16}$ As expected, the more profound mutations resulting in the lack of circulating FVIII or FIX are associated with higher risk of inhibitor development. ${ }^{17}$ Neutralizing or inactivating autoantibodies to FVIII may also develop in patients without a history of coagulation factor deficiency. This condition, known as acquired hemophilia, affects $0.2-1$ out of every million people per year. ${ }^{18}$ Despite the low incidence of acquired hemophilia, the disorder is often devastating and the costs of treatment are immense. There is therefore considerable interest in improving and optimizing existing treatment regimens. ${ }^{18,19}$

\section{Bypassing agents}

Treatment of hemophilia patients with inhibitors is based primarily on controlling or preventing acute hemorrhages and their sometimes life threatening complications. Patients with low inhibitor titers may be given high doses of factor concentrate. While some of the factor is neutralized by the inhibitors, enough remains in the circulation to induce hemostasis. Patients with high inhibitor titers ( $\geq 5$ Bethasda units, BU) cannot be treated by replacement therapy because even high doses of coagulation factor are rapidly inactivated by the circulating antibodies. ${ }^{20}$ These patients must be treated with agents capable of inducing hemostasis independent of the presence of FVIII or FIX (bypassing agents). Two such agents are in widespread use: activated prothrombin complex concentrate (aPCC, also known as factor eight inhibitor bypass activity, FEIBA, Baxter AG, Vienna, Austria) ${ }^{21}$ and recombinant activated factor VII (rFVIIa; NovoSeven, Novo Nordisk AS, Bagsværd, Denmark). ${ }^{15,22}$ rFVIIa, given at supraphysiological doses, has been approved in many countries for the treatment of bleeding episodes in patients with congenital hemophilia and inhibitors to FVIII or FIX and patients with acquired hemophilia. ${ }^{23}$ The half-life of FVIIa in the circulation is approximately 2.3 hours. ${ }^{24,25} \mathrm{In}$ most patients, bleeding episodes are therefore brought under control by administering two or three doses of $90 \mu \mathrm{g} / \mathrm{kg}$ given at two hour intervals. ${ }^{26,27}$

\section{The need for a long-acting therapy for hemophilia}

A long-acting form of FVIII would provide extended protection against bleeding and reduce gaps in protection caused by drops in FVIII levels between injections. Therefore, fewer injections would be required, resulting in fewer injection related complications, and better quality of life. Several attempts have been made to generate long-acting forms of 
FVIII. ${ }^{28}$ These included mutagenesis of the FVIII molecule to increase its stability ${ }^{29-31}$ and direct PEGylation of the FVIII protein. ${ }^{32-35}$ Modifying a large and complex protein such as FVIII is a difficult undertaking, though. The integrity of multiple active sites must be maintained and protein conformation must be preserved. Development of modified forms of FVIII is still in the preclinical stage and the safety and efficacy of these approaches has yet to be demonstrated in humans. ${ }^{28}$

There is also a clinical need for a more potent and longacting form of FVIIa. As in the case of FVIII, long-acting FVIIa would require fewer injections, would reduce injection associated complications, and would provide patients with better control of bleeding episodes with fewer dips in FVIIa levels. Several approaches have been employed in attempts to improve FVIIa. These include substitution of one or more amino acids within the protein, ${ }^{36}$ PEGylation, ${ }^{37}$ and fusion of FVIIa to albumin. ${ }^{38}$ These proteins showed promising results in-vitro and in-animal models, but as in the case of FVIII, the efficacy and safety of these approaches has yet to be demonstrated in humans.

\section{PEGylated liposome (PEGLip) technology}

Liposomes, artificial phospholipid vesicles, have proven to be useful in stabilizing drugs and improving their pharmacological properties. In most cases, liposomes are used to encapsulate the therapeutic agent (usually a small molecule drug). ${ }^{39}$ Modifying the liposome surface with molecules such as polyethylene glycol prevents adsorption of plasma proteins to the liposome surface and interferes with recognition and uptake by the reticoloendothelial system (RES). This results in the generation of liposomes with a dramatically extended circulation time..$^{40,41}$
PEGylated liposome (PEGLip) technology is a new approach to improving the pharmacodynamic properties of therapeutic proteins. Instead of encapsulating the drug, PEGylated liposomes are used as carriers with the protein bound non-covalently but with high specificity to the outer surface (Figure 1). Unlike approaches such as mutagenesis, direct PEGylation, or fusion to carrier proteins, PEGLip technology does not involve changes to a protein's amino acid sequence and does not involve covalent attachment of stabilizing agents.

The PEGLip that we typically produce are composed of a 97:3 molar ratio of 1-palmitoyl-2-oleoyl phosphatidylcholine (POPC) to 1,2 distearoyl-sn-glycero-3-phosphatidylethanolamine-N-[methoxy(polyethyleneglycol)-2000] (DSPEPEG 2000). The liposomes are prepared as follows. Lipids are dissolved in tert-butanol and lyophilized. The resulting dry lipid powder is resuspended to $110 \mathrm{mM}$ lipid in $50 \mathrm{mM}$ sodium citrate, $\mathrm{pH} 6.7$ to form liposomes. The liposomes are then down-sized by extrusion through sequentially smaller polycarbonate filters until they reach a final diameter of 80-100 nm. The PEG molecules that extend outward from the liposome surface mediate binding of FVIII, FVIIa and other proteins to the liposome surface (Figure 1). As mentioned above, the PEG molecules also limit uptake of the liposomes by the RES, thereby extending half-life in the circulation. ${ }^{42-44}$

The binding of PEGLip to FVIII and FVIIa was demonstrated in real time using surface plasmon resonance (SPR). The protein being assayed was bound to the surface of a chip and association of liposomes was measured as a liposome solution flowed over the chip. SPR measurements showed that PEGLip bind both recombinant and plasma-derived FVIII ${ }^{45,46}$ as well as FVIIa. ${ }^{47}$ PEGLip also bind additional proteins such as recombinant human granulocyte colony-stimulating

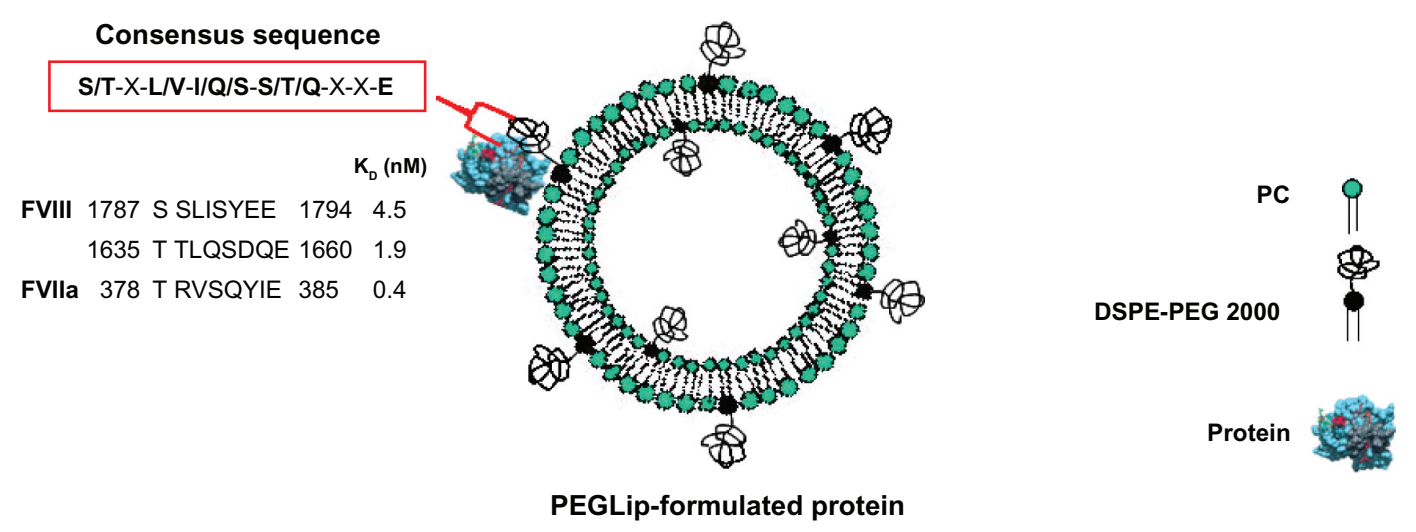

Figure I A schematic diagram showing a PEGLip formulated coagulation factor VIII (FVIII) or activated factor VII (FVIla). The protein is non-covalently bound to a polyethylene glycol moiety on the outer surface of a PEGylated liposome. Binding is mediated by an amino acid consensus sequence within the protein (boxed in red). The actual consensus sequences, locations within the proteins' sequences and affinity constants $\left(\mathrm{K}_{\mathrm{D}}\right)$ for FVIII (two binding sites) and FVIlla are shown above. 
factor (G-CSF), granulocyte macrophage colony-stimulating factor (GM-CSF), and glucagon-like peptide 1 (GLP-1). ${ }^{48}$ Affinity constants $\left(\mathrm{K}_{\mathrm{D}}\right)$ for all of these interactions were in the low $\mathrm{nM}$ range $(0.4-12 \mathrm{nM})$. All of the proteins that bind PEGLip share a consensus sequence of 8 amino acids (S/T-X-L/V-I/Q/S-S/T/Q-X-X-E) (Figure 1). A synthetic peptide derived from one of the two consensus sequences in FVIII (amino acids 1783-1796 of FVIII) also binds PEGLip with high affinity $\left(\mathrm{K}_{\mathrm{D}}\right.$ of $\left.2.3 \mathrm{nM}\right)$. PEGLip do not bind several proteins that lack the consensus sequence, highlighting its significance for binding. These proteins include human serum albumin (HSA), human IgG, insulin, interferon alpha $2 \mathrm{a}$, interferon alpha $2 \mathrm{~b}$, human growth hormone, and erythropoietin. ${ }^{48}$ Together, our data show that the consensus sequence is sufficient to mediate the binding of the proteins/ peptides to PEGLip.

We also sought to identify the molecules or structure on PEGLip responsible for protein/peptide binding. We found that non-PEGylated POPC liposomes do not bind FVIII, ${ }^{45,46}$ FVIIa, ${ }^{47}$ or the FVIII-derived synthetic peptide. ${ }^{48}$ Analyses performed with liposomes composed of various types of lipids and lipid polymers revealed that the interaction between PEGLip and proteins is mediated primarily by the PEG molecule and the carbamate group adjacent to the PEG molecule within DSPE-PEG 2000. ${ }^{48}$ When PEG molecules were not present on the liposome surface (as in the case of POPC liposomes) no binding occurred. Likewise, when proteins lacking the consensus sequence were assayed, no binding was observed. Liposome-protein binding is therefore highly specific.

\section{Formulation of FVIII and FVIla with PEGLip}

Formulation of a protein with PEGylated liposomes is very straightforward. The lyophilized protein powder of FVIII or FVIIa is simply reconstituted in liposome solution and allowed to fully dissolve. Even large and sensitive proteins such as FVIII may be formulated without any change in the production process or the purification procedure. ${ }^{45-47,49}$ Formulation is very gentle and it does not involve any covalent modification of the protein. The protein's native structure is not changed, and the likelihood of antibody production does not increase. The protein is fully active immediately after formulation ${ }^{45-47}$ and it is free to interact with its normal binding partners. ${ }^{45}$ Administration to patients remains for the most part unchanged, though dosage and frequency of injections may need to be adjusted to account for extended therapeutic activity.

\section{PEGLip-formulated FVIII}

FVIII binds PEGLip specifically and with high affinity (two binding sites, $\mathrm{K}_{\mathrm{D}}$ of 4.5 and $1.9 \mathrm{nM}$ ), but this interaction does not alter FVIII activity, as shown by maintenance of full activity after formulation. ${ }^{45,46}$ The association of FVIII with PEGLip does not affect the FVIII protein's structure. This was demonstrated by binding of several anti-FVIII antibodies to FVIII following PEGLip formulation ${ }^{45}$ Moreover, PEGLip formulation allows FVIII to interact with its natural binding partners. This was shown by in-vitro binding of PEGLipformulated FVIII to vWF. ${ }^{45}$ Thus binding of PEGLip to FVIII does not change the protein's biological properties.

PEGLip formulation of both recombinant and plasmaderived forms of FVIII extends hemostatic efficacy in vivo. This was demonstrated by better survival of hemophilic mice following tail-vein transection. Standard FVIII, PEGLipFVIII, or saline were administered to hemophilic mice 24 hours prior to transection of the left lateral tail vein. Mice that received PEGLip-FVIII bled less and survived significantly longer $(P<0.05)$ than mice that received standard FVIII or saline (Figure 2A). ${ }^{45,46}$ This significantly increased survival of tail-vein transected hemophilic mice following the injection of PEGip formulated recombinant FVIII was also demonstrated by others. ${ }^{50}$ The increased survival rate was dependent on the pre-formation of a complex of FVIII and PEGLip. Clotting times of whole blood samples from hemophilic mice injected with PEGLip-FVIII were much shorter than the clotting times of blood samples from mice injected with free FVIII. This faster clotting was detected shortly after injection and at various time points up to 72 hours post injection. ${ }^{50}$

PEGLip-FVIII provides human subjects with extended protection from bleeding. ${ }^{49}$ Several clinical trials tested the safety and the efficacy of PEGLip rFVIII (also referred to as BAY 79-4980). ${ }^{51}$ A single arm, subject blinded clinical trial was performed to assess the efficacy and safety of two levels of FVIII ( 25 or $35 \mathrm{IU} / \mathrm{kg}$ ) with a fixed dose of liposomes (22 mg lipids $/ \mathrm{kg}$ ). Twenty-three severe hemophilia A patients were treated in three study segments. Standard FVIII was administered in the first study segment whereas PEGLip-FVIII was provided in the second and third segments. Segments were separated by 4-day washout periods and each prophylactic infusion was administered while subjects were in a nonbleeding state. As a measure of efficacy, the time between each prophylactic infusion and the next spontaneous bleed was recorded. Prophylactic treatment with PEGLip-FVIII nearly doubled the length of time subjects were protected from spontaneous bleeding (Figure 2B). A single prophylactic 

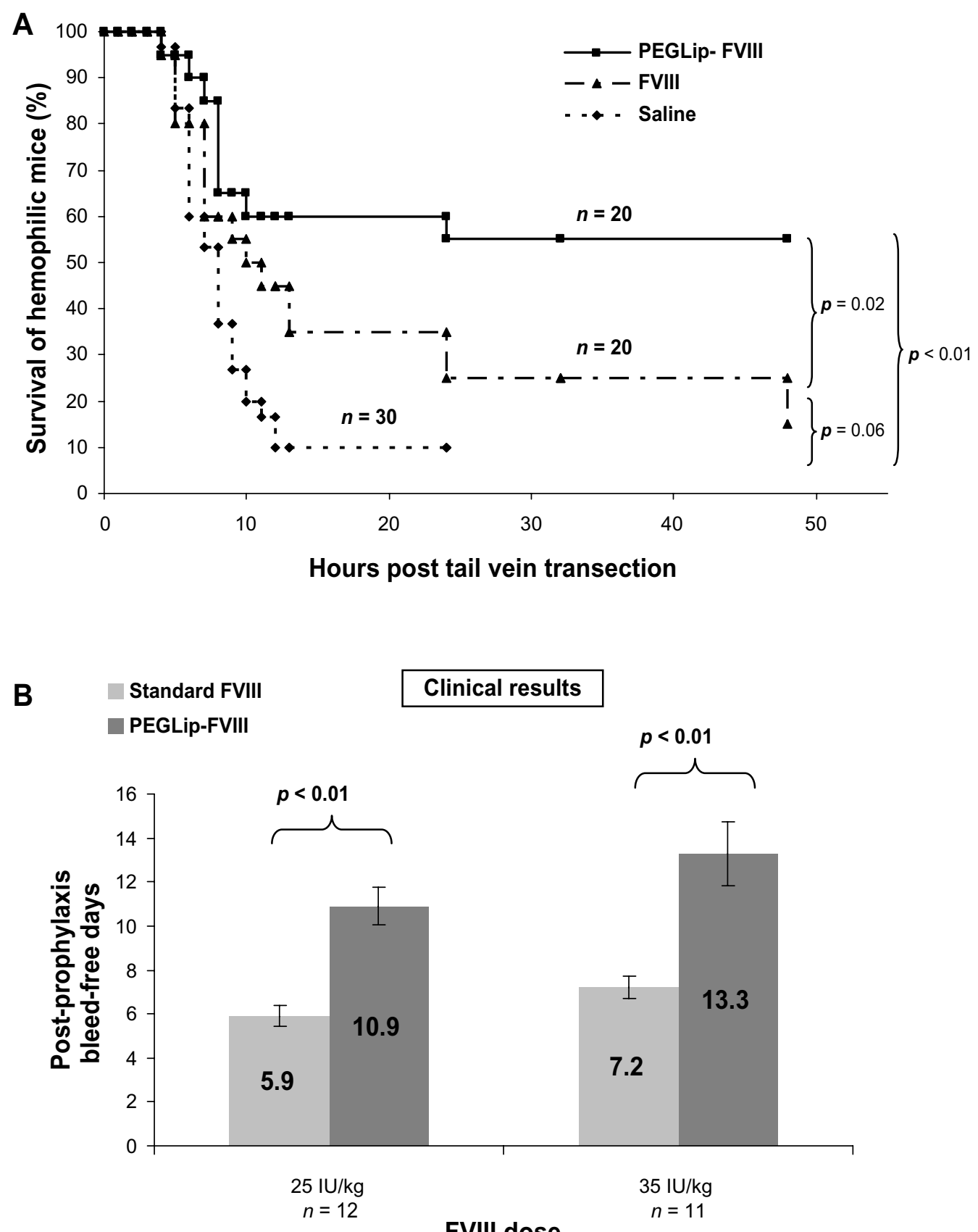

Figure 2 Efficacy of PEGLip-formulated FVIII in preclinical experiments and a clinical trial. A) Efficacy in an animal model. Hemophilic mice were injected into the tail vein with PEGLip-formulated FVIII, standard FVIII (both $0.1 \mathrm{IU} /$ mouse), or saline. Twenty-four hours after injection, the left lateral tail vein of each mouse was cut and survival was scored. B) Efficacy in a clinical trial. Hemophilia A patients were given $25 \mathrm{IU} / \mathrm{kg}$ or $35 \mathrm{IU} / \mathrm{kg}$ of standard or PEGLip-formulated FVIII and the time between the prophylactic infusion and the next spontaneous bleed was recorded. The number of bleeding-free days following each treatment is shown. Results are average \pm SEM.

injection of $25 \mathrm{IU} / \mathrm{kg}$ PEGLip-FVIII resulted in a mean bleed-free interval of 10.9 days compared to 5.9 days with standard FVIII. Similarly, injection of 35 IU/kg PEGLip-FVIII resulted in a mean bleed-free interval of 13.3 days compared to 7.2 days with standard FVIII. This difference was significant $(P<0.05)$ for both dose levels (Figure 2B). ${ }^{49}$

A subsequent randomized, subject blinded, four-way crossover study involving 16 hemophilia A patients evaluated the efficacy and safety of prophylactic infusions of various PEGLip doses $(4.2,12.6$, or $22.1 \mathrm{mg} / \mathrm{kg})$ with a fixed FVIII dose (35 IU/kg). Mean number of bleeding-free days after each infusion increased from 7.8 days for $35 \mathrm{IU} / \mathrm{ml}$ of standard FVIII to $8.7,10.8$, and 10.9 days for $35 \mathrm{IU} / \mathrm{ml}$ of FVIII formulated in 4.2, 12.6, and $22.1 \mathrm{mg} / \mathrm{kg}$ of PEGLip, respectively. ${ }^{52}$ The study showed a dose response to PEGLip that reached saturation at the highest dose level. 
An additional study tested the safety of PEGLip-FVIII and compared its pharmacokinetic profile to that of standard FVIII. ${ }^{53}$ In this randomized double-blind study, 26 severe hemophilia A patients received a single injection of standard FVIII (35 IU/kg) followed by 12 observation days and a 4-day Washout period. Patients then received a single injection of PEGLip-FVIII (35 IU/kg FVIII, 13 or $22 \mathrm{mg} / \mathrm{kg}$ PEGLip) followed once again by 12 days of observation. Pharmacokinetic (PK) analysis based on samples taken from patients during the trial showed no significant difference between standard FVIII and PEGLip-FVIII. This suggests that the increased protection from bleeding observed with PEGLip-FVIII did not result from a simple prolongation of FVIII half-life in the blood stream.

Safety and tolerability of PEGLip-FVIII were assessed in another clinical trial involving 18 severe hemophilia A patients. This study was directed primarily at determining the optimal infusion rate for PEGLip-FVIII. The study showed that PEGLip-FVIII may be administered at an infusion rate similar to that of standard FVIII. ${ }^{54}$

In all four of the studies described above, no production of inhibitory antibodies was detected, and no serious adverse events were reported. However, a few subjects experienced increased breathing frequency and flushing. ${ }^{53,54}$ At the first sign of symptoms, infusions were stopped and the patients recovered fully without further medical intervention. This type of hypersensitivity reaction is known as complement activation related pseudoallergy (CARPA) and has been described following administration of radiocontrast media, liposomal drugs, and micellar solvents. Unlike IgE mediated reactions, CARPA reactions arise at first treatment and become milder or disappear upon repeated exposure..$^{54,55}$

The combined results of the phase I and II clinical studies described above show that PEGLip-FVIII is well tolerated and provides extended protection from bleeding following prophylactic treatment.

\section{PEGLip-formulated FVIla}

PEGLip formulation is desirable for FVIIa because this therapeutic protein has an extremely short half-life in the circulation (approximately 2.3 hours). ${ }^{24,25}$ In most patients treated with FVIIa, effective hemostasis is achieved only after two or three doses of $90 \mu \mathrm{g} / \mathrm{kg}^{26,27}$ given at two hour intervals.

SPR analyses showed that PEGLip bind specifically to FVIIa. As in the case of FVIII, binding of liposomes to FVIIa was dependant on the presence of the DSPE-PEG lipopolymer. POPC liposomes lacking DSPE-PEG bound FVIIa to a much lower level than PEGLip. Kinetic analysis of the PEGLipFVIIa interaction indicated that the PEGLip bind to FVIIa with an affinity $\left(\mathrm{K}_{\mathrm{D}}\right)$ of $0.4 \mathrm{nM} .{ }^{47}$ Formulation of FVIIa with PEGLip did not affect its in vitro activity. ${ }^{47}$ Most importantly, formulation of FVIIa with PEGLip improved survival of hemophilic mice following tail vein transection. Hemophilic mice were injected with standard FVIIa, PEGLip-FVIIa, or saline. Fifteen minutes after injection, tail veins were transected and survival was scored up to 24 hours. We found that mice injected with PEGLip-FVIIa survived significantly longer $(P<0.05)$ than mice injected with standard FVIIa (Figure 3A).

The safety and efficacy of PEGLip-FVIIa were tested in humans in an open label, exploratory, cross over, phase I/II clinical study in six adult subjects with severe hemophilia A and inhibitory FVIII antibodies. ${ }^{56}$ Each subject received two infusions: one infusion of $90 \mu \mathrm{g} / \mathrm{kg}$ standard FVIIa and one infusion of $90 \mu \mathrm{g} / \mathrm{kg}$ PEGLip-formulated FVIIa. The two infusions were separated by a 10-day washout period. Injection volume was kept constant while injection order was randomized. Blood samples were collected from patients at various time points both before and after each infusion of FVIIa or PEGLip-FVIIa. Whole blood samples were then analyzed by rotational thrombelastography, a method recording the kinetics of clot formation and the firmness of the clots. PEGLip-formulated FVIIa produced significantly $(P<0.05)$ shorter clotting times and higher clot firmness than standard FVIIa up to 5 hours post injection. Clotting time of standard FVIIa 30 min post injection was the same as clotting time of PEGLip-FVIIa 2 hours post injection. Clotting time of standard FVIIa 1 hour post injection was the same as clotting time of PEGLip-FVIIa 3.2 hours post injection (Figure 3B). Maximal clot firmness induced by standard FVIIa 0.5 hour post injection was as high as that induced by PEGLip-FVIIa $\sim 2.7$ hours post injection. Thrombin generation assays showed that thrombin was produced faster and more efficiently following infusion of PEGLip-FVIIa than following infusion of standard FVIIa. No significant differences were detected between the PK of PEGLip-FVIIa and standard FVIIa.

One of the subjects in the trial experienced transient hyperemia, an increase in blood pressure and anxiety during the infusion of the first $1 \mathrm{~mL}$ of PEGLip-FVIIa. This non-IgE mediated reaction (CARPA) is associated with PEGLip. ${ }^{55}$ and is not related to FVIIa. The reaction subsided within one hour. In all other subjects, PEGLip-FVIIa was well tolerated and there were no serious adverse events nor were there any significant changes in vital signs, clinical chemistry or hematological parameters. Measurements of coagulation parameters indicated that there was no increase in thrombotic risk.

An analysis of the results of the clinical trial indicates that PEGLip-FVIIa provides about two more "efficacy hours" 

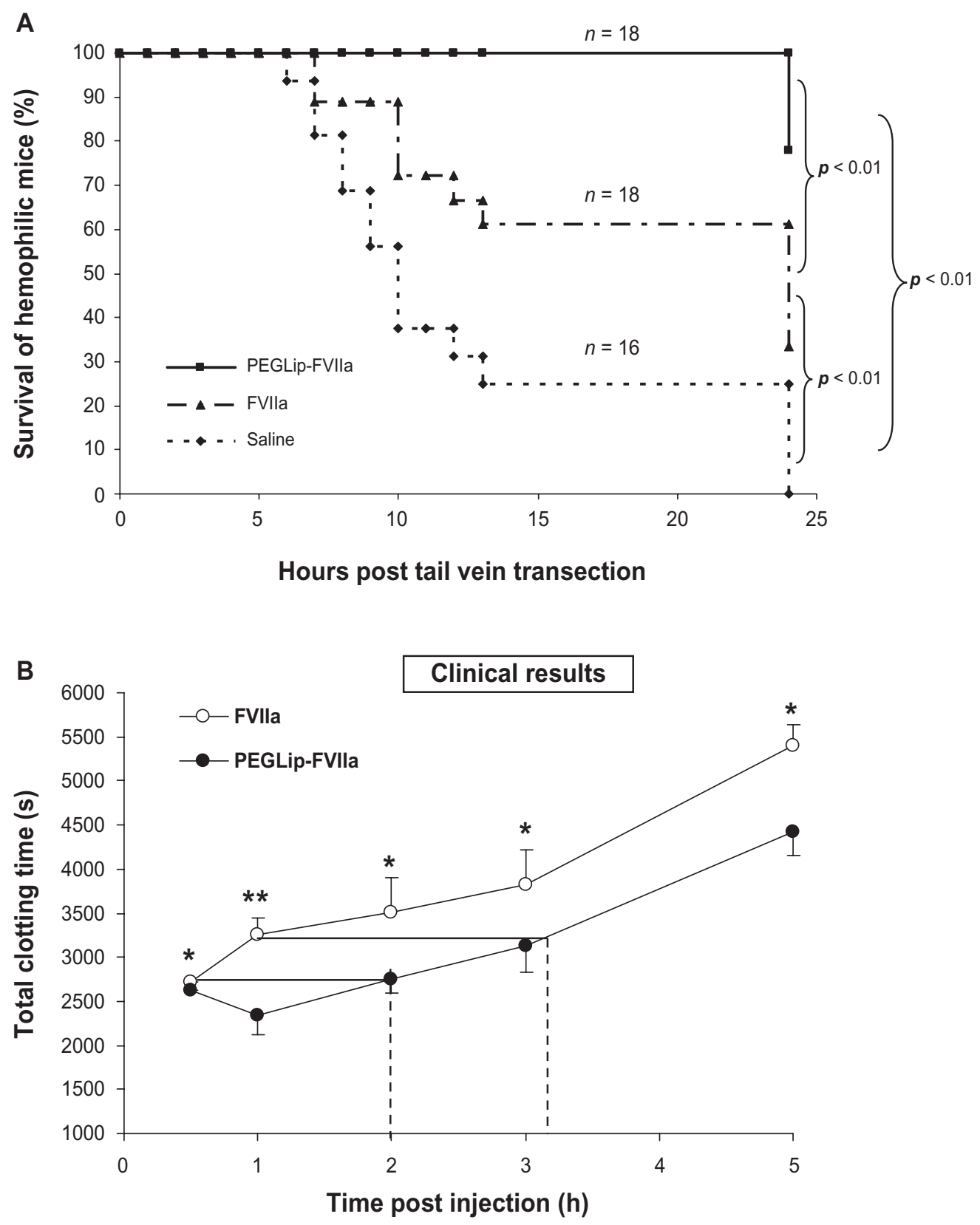

Figure 3 Efficacy of PEGLip-formulated FVIla in preclinical experiments and a clinical trial. A) Efficacy in an animal model. Hemophilic mice were injected with PEGLip-FVIla, standard FVlla (both $10 \mu \mathrm{g} /$ mouse), or saline. The right and left lateral tail veins of each mouse were cut 15 min post injection and survival was scored. B) Efficacy in a clinical trial. Hemophilia patients with inhibitors were injected prophylactically with $90 \mu \mathrm{g} / \mathrm{kg}$ FVlla (o) or $90 \mu \mathrm{g} / \mathrm{kg}$ PEGLip-FVIla (•). Total clotting times at $0.5-5$ hours post injection were analyzed by thrombelastography. No clotting (total clotting time $>3600 \mathrm{sec}$ ) was detected in any of the subjects in the hour preceding infusions. The dashed lines compare clotting times induced by PEGLip-FVlla to those induced by standard FVlla. Results are average \pm SEM $(n=6) .{ }^{*} P<0.05,{ }^{* *} P=0.08$ (FVlla vs PEGLip-FVlla, paired t-test).

than standard FVIIa. In treatment of bleeding episodes in hemophilia patients with inhibitors, one $90 \mu \mathrm{g} / \mathrm{kg}$ dose of PEGLip-FVIIa may be roughly equivalent to two infusions of standard FVIIa given at 2-hour intervals.

\section{Mechanism of action}

In preclinical models, formulation of FVIII and FVIIa with PEGLip improved pharmacokinetic properties in vivo and increased circulation half-life. ${ }^{45-47}$ However, phase I clinical experiments showed that there was no difference between the pharmacokinetic behavior of standard FVIII and PEGLip-formulated FVIII ${ }^{53}$ and between standard FVIIa and PEGLip-formulated FVIIa. ${ }^{56}$ This suggests that extension of circulation half-life is not the primary mechanism responsible for increased hemostatic efficacy.

Extensive in vitro experiments measuring clot formation and lysis by rotational thrombelastography, indicate that platelets must be present in order for PEGLip formulation to 
improve the hemostatic properties of FVIII and FVIIa. ${ }^{47,57}$ When PEGLip-FVIII and PEGLip-FVIIa were added to severe hemophilic whole blood or platelet rich plasma, clots formed much faster than when similar concentrations of standard FVIII and FVIIa were used. Clots were also firmer and more resistant to fibrinolysis. Similarly, ex-vivo rotational thrombelastometry experiments in whole blood drawn from hemophilic mice indicated that clotting times were much faster in mice injected with PEGLip-FVIII rather than with free FVIII. ${ }^{50}$ Such improvements in kinetics, clot firmness, and resistance to fibrinolysis depended on platelets as they were not observed when experiments were performed in platelet poor plasma. ${ }^{57}$

In order to gain a deeper understanding of the mechanisms responsible for these improvements in efficacy, we tested whether PEGLip themselves bind platelets. Flow cytometry analysis indicated that fluorescent PEGLip associate with platelets in-vitro in a dose related manner. This association was further confirmed in-vivo following the injection of fluorescent PEGLip into hemophilic mice. ${ }^{57}$ Interactions between liposomes of various compositions, including PEG liposomes, and blood cells have been reported previously by others. ${ }^{50,58}$

Having shown that PEGLip bind FVIII and FVIIa ${ }^{45,47}$ and that PEGLip bind platelets, we next tested whether PEGLip are capable of delivering proteins to platelets. Fluorescently labeled FVIII and FVIIa were formulated with non-fluorescent PEGLip and shown by flow cytometry to bind human platelets in-vitro. These results were also found in-vivo as PEGLip-formulated fluorescent proteins interacted with the platelets of hemophilic mice following injection. ${ }^{57}$ Fluorescently labeled human serum albumin (HSA), which does not bind to PEGLip, did not show increased binding to platelets following formulation with PEGLip. This indicates that PEGLip-mediated association of proteins with platelets is dependent on prior binding of the proteins to PEGLip.

The combined results indicate the following mechanism (Figure 4): Formulation of FVIII or FVIIa with PEGLip leads to non-covalent binding of the protein to the outer surface of

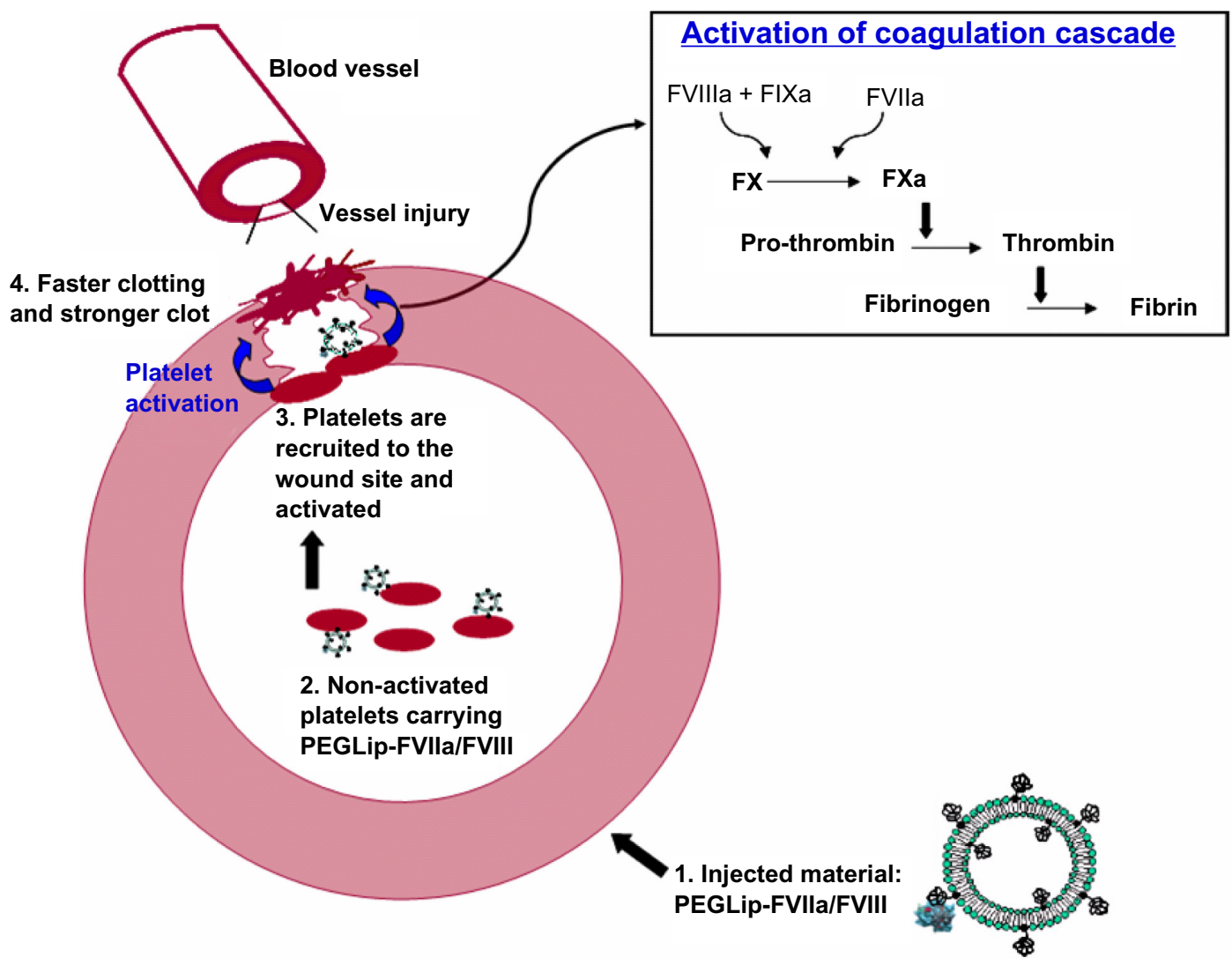

Figure 4 Mechanism of action of PEGLip-formulated FVIII and FVIla.

I. Formulation of FVIII or FVIla with PEGLip leads to non-covalent binding of the protein to the outer surface of the PEGylated liposomes.

2. The liposomes are then injected into the bloodstream where they associate with non-activated platelets.

3. When injury occurs, platelets are recruited to the wound where they adhere to the damaged vessel wall. They carry FVIII and FVIla with them. Platelet activation and initiation of the coagulation cascade occur simultaneously.

4. Coagulation complexes form on the surface of the activated platelets. Since FVIII and FVIla are already present on the platelets prior to activation, the coagulation cascade is more efficient. Clots form faster and the clots are more stable. 
the PEGylated liposomes. After injection of the formulated proteins to the bloodstream the liposomes associate with non-activated platelets and a complex of platelet-PEGLipprotein (FVIII/FVIIa) is formed in-vivo. Following injury, platelets are recruited to sites of injury where they adhere to the damaged vessel wall. Due to their prior association with PEGLip, they carry FVIII and FVIIa with them. Platelets are activated at the wound site and coagulation complexes form on the surface of the activated platelets. Since FVIII and FVIIa are already present on the platelets prior to activation, the coagulation cascade is more efficient. Clots form faster and the clots are more stable.

The association of PEGLip-FVIII or PEGLip-FVIIa with platelets may also lead to increased concentration of FVIII or FVIIa at the wound site, even when the overall concentration of FVIII or FVIIa in the circulation is low. Accordingly, expression of FVIII in platelets was shown to be effective at inducing hemostasis even when FVIII protein expression levels did not exceed $1 \%$ of normal levels. This was probably due to recruitment of platelets to the sites of injury and local release of FVIII from activated platelets at wound sites. ${ }^{59}$

\section{Summary}

PEGLip technology improves the pharmacodynamic properties of both coagulation factors VIII and VIIa. This was demonstrated in preclinical experiments and in five different clinical trials with both FVIII and FVIIa. The combined results indicate that PEGLip-FVIII prevents bleeding for a significantly longer period than standard FVIII, and that one dose of PEGLip-FVIIa may be roughly equivalent to two infusions of standard FVIIa given at 2 hour intervals when treating a bleed in hemophilia patients with inhibitors.

Of the approaches currently available to generate longacting forms of FVIII and FVIIa, PEGLip formulation has the advantage of being the only approach that has been tested extensively in clinical trials. PEGLip-FVIII and PEGLipFVIIa have been shown to be safe in trials involving more than 90 hemophilia patients. In general, treatments with PEGLip-formulated FVIII and FVIIa were well tolerated.

One of the most problematic complications of hemophilia treatment is the induction of inhibitory antibodies. PEGLip formulation does not change the structure of FVIII and FVIIa. It thereby avoids one of the biggest obstacles to producing improved coagulation factors: changes in structure that induce antibody formation. Because of the large size and complexity of the FVIII protein and the sensitivity of hemophilia A patients to even small changes in the protein, ${ }^{60,61}$ FVIII can be considered a worst case scenario for increased immunogenicity. Extensive experience with PEGLip-FVIII in several clinical studies has shown no increase in antibody generation. PEGLip formulation thus avoids one of the major pitfalls of the drug development process. ${ }^{49,52,53}$

PEGLip-FVIII/FVIIa are well tolerated and suitable for long-term treatment of hemophilia. This was demonstrated in toxicology studies, which included injecting high doses of PEGLip-FVIII and PEGip-FVIIa into rats and rabbits (acute toxicology) and repeated injections (up to nine months of weekly injections) of PEGLip into rats and rabbits. ${ }^{45}$ PEGylated liposomes were also shown to be non-toxic in mice and dogs. ${ }^{62}$

In the years to come, we expect PEGLip-FVIII and PEGLip-FVIIa to become an attractive treatment for hemophilia A patients and hemophilia patients with inhibitors.

\section{Disclosure}

The authors are employees of Omri Laboratories Ltd. The authors report no conflicts of interest in this work.

\section{References}

1. Dahlback B. Blood coagulation and its regulation by anticoagulant pathways: genetic pathogenesis of bleeding and thrombotic diseases. J Intern Med. 2005;257:209-223.

2. Hedner U, Ginsburg D, Lusher JM, High KA. Congenital Hemorrhagic Disorders: New Insights into the Pathophysiology and Treatment of Hemophilia. Hematology Am Soc Hematol Educ Program. 2000: 241-265.

3. Soucie JM, Evatt B, Jackson D. Occurrence of hemophilia in the United States. The Hemophilia Surveillance System Project Investigators. Am J Hematol. 1998;59:288-294.

4. Kaufman RJ, Anthonorakis SE, Fay PJ. Hemostasis and Thrombosis: Basic Principles and Clinical Practice. 4th ed. Philadelphia: Lippincott Williams and Wilkins, 2001.

5. Roosendaal G, Mauser-Bunschoten EP, De Kleijn P, et al. Synovium in haemophilic arthropathy. Haemophilia. 1998;4:502-505.

6. Arun B, Kessler C. Inherited hemorrhagic disorders. In: Colman W, Hirsh J, Marder V, Clowes A, George J, editors. Hemostasis and thrombosis. 4th ed. Philadelphia: Lippincott Williams \& Willkins, 2001:815-825.

7. Hoots WK, Nugent DJ. Evidence for the benefits of prophylaxis in the management of hemophilia A. Thromb Haemost. 2006;96:433-440.

8. Kessler CM. New perspectives in hemophilia treatment. Hematology Am Soc Hematol Educ Program. 2005:429-435.

9. Jankowski MA, Patel H, Rouse JC, Marzilli LA, Weston SB, Sharpe PJ. Defining 'full-length' recombinant factor VIII: a comparative structural analysis. Haemophilia. 2007;13:30-37.

10. Fijnvandraat K, Berntorp E, ten Cate JW, et al. Recombinant, B-domain deleted factor VIII (r-VIII SQ): pharmacokinetics and initial safety aspects in hemophilia A patients. Thromb Haemost. 1997;77:298-302.

11. Weiss HJ, Sussman, II, Hoyer LW. Stabilization of factor VIII in plasma by the von Willebrand factor. Studies on posttransfusion and dissociated factor VIII and in patients with von Willebrand's disease. J Clin Invest. 1977;60:390-404.

12. Santagostino E, Mancuso ME. Barriers to primary prophylaxis in haemophilic children: the issue of the venous access. Blood Transfus. 2008;6:S12-S16.

13. Saenko EL, Ananyeva NM, Moayeri M, Ramezani A, Hawley RG. Development of improved factor VIII molecules and new gene transfer approaches for hemophilia A. Curr Gene Ther. 2003;3:27-41. 
14. Mathew P. Current opinion on inhibitor treatment options. Semin Hematol. 2006;43:S8-S13.

15. Lusher JM, Roberts HR, Davignon G, et al. A randomized, double-blind comparison of two dosage levels of recombinant factor VIIa in the treatment of joint, muscle and mucocutaneous haemorrhages in persons with haemophilia A and B, with and without inhibitors. rFVIIa Study Group. Haemophilia. 1998;4:790-798.

16. Shapiro A. Inhibitor treatment: state of the art. Dis Mon. 2003;49: 22-38.

17. Rick ME, Walsh CE, Key NS. Congenital bleeding disorders. Hematology Am Soc Hematol Educ Program. 2003:559-574.

18. Zeitler H, Ulrich-Merzenich G, Hess L, et al. Treatment of acquired hemophilia by the Bonn-Malmo Protocol: documentation of an in vivo immunomodulating concept. Blood. 2005;105:2287-2293.

19. Ma AD, Carrizosa D. Acquired factor VIII inhibitors: pathophysiology and treatment. Hematology Am Soc Hematol Educ Program. 2006: 432-437.

20. Kempton CL, White GC 2nd. How we treat a hemophilia A patient with a factor VIII inhibitor. Blood. 2009;113:11-17.

21. Tjonnfjord GE, Holme PA. Factor eight inhibitor bypass activity (FEIBA) in the management of bleeds in hemophilia patients with high-titer inhibitors. Vasc Health Risk Manag. 2007;3:527-531.

22. Hedner U, Glazer S, Pingel K, et al. Successful use of recombinant factor VIIa in patient with severe haemophilia A during synovectomy. Lancet. 1988;2:1193.

23. Ingerslev J. Efficacy and safety of recombinant factor VIIa in the prophylaxis of bleeding in various surgical procedures in hemophilic patients with factor VIII and factor IX inhibitors. Semin Thromb Hemost. 2000;26:425-432.

24. Fridberg MJ, Hedner U, Roberts HR, Erhardtsen E. A study of the pharmacokinetics and safety of recombinant activated factor VII in healthy Caucasian and Japanese subjects. Blood Coagul Fibrinolysis. 2005; 16:259-266.

25. Lindley CM, Sawyer WT, Macik BG, et al. Pharmacokinetics and pharmacodynamics of recombinant factor VIIa. Clin Pharmacol Ther. 1994;55:638-648.

26. Ingerslev J, Thykjaer $H$, Kudsk Jensen O, Fredberg U. Home treatment with recombinant activated factor VII: results from one centre. Blood Coagul Fibrinolysis. 1998;9:S107-S110.

27. Key NS, Aledort LM, Beardsley D, et al. Home treatment of mild to moderate bleeding episodes using recombinant factor VIIa (Novoseven) in haemophiliacs with inhibitors. J Thromb Haemost. 1998;80: 912-918.

28. Saenko EL, Pipe SW. Strategies towards a longer acting factor VIII. Haemophilia. 2006;12 Suppl 3:42-51.

29. Gale AJ, Pellequer JL. An engineered interdomain disulfide bond stabilizes human blood coagulation factor VIIIa. J Thromb Haemost. 2003;1:1966-1971.

30. Gale AJ, Radtke KP, Cunningham MA, Chamberlain D, Pellequer JL, Griffin JH. Intrinsic stability and functional properties of disulfide bond-stabilized coagulation factor VIIIa variants. J Thromb Haemost. 2006;4:1315-2132.

31. Pipe SW, Kaufman RJ. Characterization of a genetically engineered inactivation-resistant coagulation factor VIIIa. Proc Natl Acad Sci U SA. 1997;94:11851-11856.

32. Mei B, Pan C, Jiang H, et al. Rational design of a fully active, longacting PEGylated factor VIII for hemophilia A treatment. Blood.

33. Murphy JE, Pan C, Barnett T, et al. Site-specific PEGylation of rFVIII results in prolonged in vivo efficacy. J Thromb Haemost. 2007;5: P-T-022.

34. Regan LM, Jiang X, Ramsey P, et al. Biological activity of PEGylated factor VIII. J Thromb Haemost. 2007;5:P-T-026.

35. Tang L, Pan C, Atwal H, et al. PEGylation protects factor VIII from the inhibition of antibody inhibitors. J Thromb Haemost. 2007;5: P-T-036.
36. Allen GA, Persson E, Campbell RA, Ezban M, Hedner U, Wolberg AS. A variant of recombinant factor VIIa with enhanced procoagulant and antifibrinolytic activities in an in vitro model of hemophilia. Arterioscler Thromb Vasc Biol. 2007;27:683-689.

37. Stennicke HR, Ostergaard H, Bayer RJ, et al. Generation and biochemical characterization of glycoPEGylated factor VIIa derivatives. J Thromb Haemost. 2008;100:920-928.

38. Schulte S. Use of albumin fusion technology to prolong the half-life of recombinant factor VIIa. Thromb Res. 2008;122:S14-S19.

39. Zamboni WC. Concept and clinical evaluation of carrier-mediated anticancer agents. Oncologist. 2008;13:248-260.

40. Elbayoumi TA, Torchilin VP. Liposomes for targeted delivery of antithrombotic drugs. Expert Opin Drug Deliv. 2008;5:1185-1198.

41. Gabizon A, Shmeeda H, Barenholz Y. Pharmacokinetics of pegylated liposomal Doxorubicin: review of animal and human studies. Clin Pharmacokinet. 2003;42:419-436.

42. Gabizon A, Catane R, Uziely B, et al. Prolonged circulation time and enhanced accumulation in malignant exudates of doxorubicin encapsulated in polyethylene-glycol coated liposomes. Cancer Res. 1994; 54:987-992.

43. Gabizon AA, Barenholz Y, Bialer M. Prolongation of the circulation time of doxorubicin encapsulated in liposomes containing a polyethylene glycol-derivatized phospholipid: pharmacokinetic studies in rodents and dogs. Pharm Res. 1993;10:703-708.

44. Klibanov AL, Maruyama K, Torchilin VP, Huang L. Amphipathic polyethyleneglycols effectively prolong the circulation time of liposomes. FEBS Lett. 1990;268:235-237.

45. Baru M, Carmel-Goren L, Barenholz Y, et al. Factor VIII efficient and specific non-covalent binding to PEGylated liposomes enables prolongation of its circulation time and haemostatic efficacy. J Thromb Haemost. 2005;93:1061-1068.

46. Dayan I, Robinson M, Baru M. Enhancement of haemostatic efficacy of plasma-derived FVIII by formulation with PEGylated liposomes. Haemophilia. 2009;15:1006-1013.

47. Yatuv R, Dayan I, Carmel-Goren L, et al. Enhancement of factor VIIa haemostatic efficacy by formulation with PEGylated liposomes. Haemophilia. 2008;14:476-483.

48. Yatuv R, Carmel-Goren L, Dayan I, Robinson M, Baru M. Binding of proteins to PEGylated liposomes and improvement of G-CSF efficacy in mobilization of hematopoietic stem cells. $J$ Control Release. 2009; 135:44-50.

49. Spira J, Plyushch OP, Andreeva TA, Andreev Y. Prolonged bleedingfree period following prophylactic infusion of recombinant factor VIII reconstituted with pegylated liposomes. Blood. 2006;108:3668-3673.

50. Pan J, Liu T, Kim JY, et al. Enhanced efficacy of recombinant FVIII in noncovalent complex with PEGylated liposome in hemophilia A mice. Blood. 2009;114:2802-2811.

51. Powell JS. Liposomal approach towards the development of a longeracting factor VIII. Haemophilia. 2007;13:23-28.

52. Spira J, Plyushch OP, Andreeva TA, Khametova RN. Evaluation of liposomal dose in recombinant factor VIII reconstituted with pegylated liposomes for the treatment of patients with severe haemophilia A. J Thromb Haemost. 2008;100:429-434.

53. Powell JS, Nugent DJ, Harrison JA, et al. Safety and pharmacokinetics of a recombinant factor VIII with pegylated liposomes in severe hemophilia A. J Thromb Haemost. 2008;6:277-283.

54. Martinowitz U, Lalezari S, Luboshitz J, Lubetsky A, Spira J. Infusion rates of recombinant FVIII-FS with PEGylated liposomes in haemophilia A. Haemophilia. 2008;14:1122-1124.

55. Szebeni J. Complement activation-related pseudoallergy: a new class of drug-induced acute immune toxicity. Toxicology. 2005;216:106-121.

56. Spira J, Plyushch OP, Zozulya N, et al. Safety, pharmacokinetics and efficacy of factor VIIa formulated with PEGylated liposomes in haemophilia A patients with inhibitors to factor VIII. An open label, exploratory, cross over, phase I/II study. Haemophilia. 2010; In Press. 
57. Yatuv R, Robinson M, Dayan I, Baru M. Enhancement of the efficacy of therapeutic proteins by formulation with PEGylated liposomes; a case of FVIII, FVIIa and G-CSF. Expert Opin Drug Deliv. 2010;7:187-201.

58. Constantinescu I, Levin E, Gyongyossy-Issa M. Liposomes and blood cells: a flow cytometric study. Artif Cells Blood Substit Immobil Biotechnol. 2003;31:395-424.

59. High KA. The leak stops here: platelets as delivery vehicles for coagulation factors. J Clin Invest. 2006;116:1840-1842.

60. Laub R, Di Giambattista M, Fondu P, et al. Inhibitors in German hemophilia A patients treated with a double virus inactivated factor VIII concentrate bind to the C2 domain of FVIII light chain. J Thromb Haemost. 1999;81:39-44.
61. Raut S, Di Giambattista M, Bevan SA, Hubbard AR, Barrowcliffe TW, Laub R. Modification of factor VIII in therapeutic concentrates after virus inactivation by solvent-detergent and pasteurisation. J Thromb Haemost. 1998;80:624-631.

62. Kanter PM, Bullard GA, Pilkiewicz FG, Mayer LD, Cullis PR, Pavelic ZP. Preclinical toxicology study of liposome encapsulated doxorubicin (TLC D-99): comparison with doxorubicin and empty liposomes in mice and dogs. In Vivo. 1993;7:85-95.
International Journal of Nanomedicine

\section{Publish your work in this journal}

The International Journal of Nanomedicine is an international, peerreviewed journal focusing on the application of nanotechnology in diagnostics, therapeutics, and drug delivery systems throughout the biomedical field. This journal is indexed on PubMed Central, MedLine, CAS, SciSearch $®$, Current Contents $® /$ Clinical Medicine,

\section{Dovepress}

Journal Citation Reports/Science Edition, EMBase, Scopus and the Elsevier Bibliographic databases. The manuscript management system is completely online and includes a very quick and fair peer-review system, which is all easy to use. Visit http://www.dovepress.com/ testimonials.php to read real quotes from published authors.

Submit your manuscript here: http://www.dovepress.com/international-journal-of-nanomedicine-journal 